\title{
Delayed cardiac perforation due to migrating pacemaker lead
}

\author{
Anastasia Oikonomou MD PhD, Soultana Foutzitzi MD, Panos Prassopoulos MD PhD
}

Previously published at www.cmaj.ca

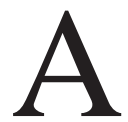

n 84-year-old woman with complete atrioventricular block underwent implantation of a dual-chamber pacemaker with passive fixation leads. The settings of the pacemaker were normal, and chest radiographs 2 and 24 hours after implantation confirmed appropriate positioning of the two leads. At one-month follow-up, the patient complained of chest pain and breathlessness that had started one week earlier and had progressively worsened. A chest radiograph showed the pacemaker lead projecting over the left hemidiaphragm. A computed tomography scan showed that the lead had perforated the myocardium of the right ventricular apex and the left hemidiaphragm; the tip of the lead was lodged in the left subdiaphragmatic space (Figure 1). During thoracotomy, the lead was found be moving freely in the left subdiaphragmatic space with no pericardial hemorrhage. The old lead was removed, and a new epicardial lead was positioned successfully.

Cardiac perforation is a well recognized - although infrequently reported - complication of pacemaker implantation $(0.3 \%-1.0 \%) .^{1}$ It usually occurs during implantation, and is less common after 24 hours; hemopericardium may or may not occur. Chest pain or shortness of breath after insertion of a pacemaker is unusual and must be investigated promptly to exclude cardiac perforation. Delayed perforation by pacemaker leads (in this patient, one month after implantation) is uncommon. ${ }^{2}$

Clinical predictors of cardiac perforation after pacemaker implantation are older age, use of corticosteroids, temporary pacing and active fixation leads. ${ }^{3}$ Our patient was older, and passive fixation leads were used. Forces at the lead tip of a pacemaker are complex, vary during the cardiac cycle and may change over time. ${ }^{4}$ If chest radiography shows that the tip appears to have migrated beyond the pericardium, a computed tomography scan should be done to confirm the diagnosis. Surgery is required to find the site of perforation and repair adjacent structures. ${ }^{2}$ Delayed development of chest, pericarditic or pleuritic pain after implantation of a pacemaker warrants a high level of suspicion for cardiac perforation by a lead, regardless of the method used to fix the lead tips.

From the Department of Radiology, Democritus University of Thrace, Alexandroupolis, Greece

CMAJ 2010. DOI:10.1503/cmaj.091352

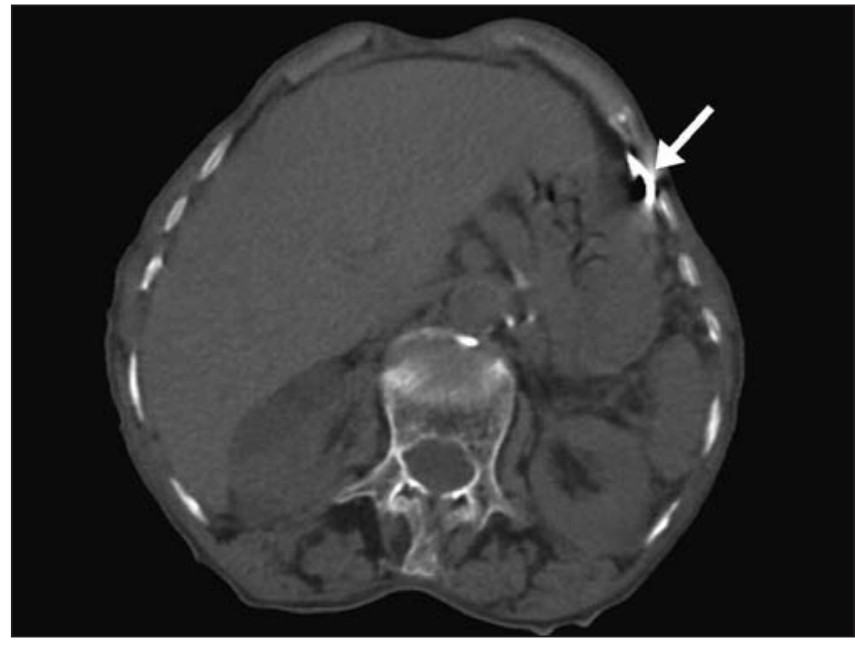

Figure 1: Unenhanced computed tomography of the thorax in an 84-year-old woman one month after implantation of pacemaker showing the lead (arrow) penetrating the left hemidiaphragm and the tip lodging in the subdiaphragmatic space.

This article has been peer reviewed.

Competing interests: None declared.

\section{REFERENCES}

1. Akyol A, Aydin A, Erdinler I, et al. Late perforation of the heart, pericardium, and diaphragm by an active-fixation ventricular lead. Pacing Clin Electrophysiol 2005;28:350-1.

2. Singhal S, Cooper JM, Cheung AT, et al. Rib perforation from a right ventricular pacemaker lead. Circulation 2007;115:e391-2.

3. Mahapatra S, Bybee KA, Bunch TJ, et al. Incidence and predictors of cardiac perforation after permanent pacemaker placement. Heart Rhythm 2005;2:907-11.

4. Ramirez MF, Ching CK, Ho KL, et al. "The attack of the $52 \mathrm{~cm}$ lead": an unusual case of late cardiac perforation by a passive-fixation permanent pacemaker lead. Int J Cardiol 2007;115:e5-7.

Clinical images are chosen because they are particularly intriguing, classic or dramatic. Submissions of clear, appropriately labelled high-resolution images must be accompanied by a figure caption and the patient's written consent for publication. A brief explanation (300 words maximum) of the educational significance of the images with minimal references is required. 